\title{
EPICARDIAL CLIP CLOSURE OF THE LEFT ATRIAL APPENDAGE: REPLY
}

\author{
Fabrizio Rosati ${ }^{1}$, Gijs de Maat ${ }^{2}$, Mattia A. E. Valente ${ }^{2}$, Massimo Mariani ${ }^{3}$, and Stefano \\ Benussi $^{1}$ \\ ${ }^{1}$ University of Brescia \\ ${ }^{2}$ University Medical Centre Groningen \\ ${ }^{3} \mathrm{UMCG}$
}

November 15, 2021

\begin{abstract}
Epicardial surgical clip is showed to be a safe and effective tool in order to achieve a complete left atrial appendage (LAA) exclusion thus reducing the risk of stroke in patients with atrial fibrillation. Historically, other methods as surgical ligation, internal oversewing or external stapling showed to be largely uneffective with an incidence of LAA residual flow ranging from $25 \%$ to $35 \%$ thus, increasing per se 5 - to 10 -fold the risk of stroke. Epicardial LAA exclusion by means of external clip could be potentially released under transesophageal echocardiographic guidance thus increasing the procedural success rate of complete closure with no residual stump left.
\end{abstract}

\section{Hosted file}

Final Reply.doc available at https://authorea.com/users/389313/articles/545553-epicardialclip-closure-of-the-left-atrial-appendage-reply 